\title{
OMNILATERALIDADE E AS CONCEPÇÕES BURGUESAS DE EDUCAÇÃO INTEGRAL
}

\author{
Paulo Aparecido Dias da Silva
}

\begin{abstract}
RESUMO
O trabalho tem por objetivo discutir, a partir de uma pesquisa bibliográfica, o conceito de omnilateralidade na perspectiva marxista em contraposição às concepções burguesas de educação integral difundidas no âmbito da educação básica brasileira. A partir dos aportes teóricos de Marx e Engels (1987; 2004; 2007), Saviani (2010; 2013), Duarte (1999; 2008; 2010), Pistrak (2003; 2009) e Lombardi (2010) busca-se demonstrar os limites das concepções burguesas de educação integral tendo em vista a não consideração dos determinantes sociais e econômicos no interior do modo de produção capitalista que impedem o livre desenvolvimento da individualidade humana e impossibilitam a apropriação dos conhecimentos produzidos historicamente pela humanidade por todos os indivíduos. Desta forma, a educação no âmbito da sociedade capitalista, está reduzida a uma formação unilateral objetivando reproduzir o estado de coisas vigente nesta mesma sociedade. No entanto, cabe destacar que esse processo ocorre de forma contraditória tem em vista que a apropriação de conhecimentos científicos no interior do modo de produção capitalista possibilita a intervenção revolucionária na realidade.

Palavras-chave: Educação Integral; Omnilateralidade; Individualidade para-si.
\end{abstract}

\section{OMNILATERALITY AND BOURGEOIS CONCEPTS OF INTEGRAL EDUCATION}

\begin{abstract}
The work aims to discuss, from a literature review, the concept of omnilaterality from the Marxist perspective as opposed to bourgeois conceptions of integral education disseminated within the Brazilian basic education. From the theoretical contributions of Marx and Engels (1987; 2004; 2007), Saviani (2010; 2013), Duarte (1999; 2008; 2010), Pistrak (2003; 2009) and Lombardi (2010) the work seeks to demonstrate the limits bourgeois conceptions of integral education with a view to not address social and economic determinants within the capitalist mode of production that prevents the free development of human individuality, and preclude the acquisition of knowledge historically produced by humanity for all individuals. Thus, is possible to see that education, in the framework of capitalist society, is reduced to a unilateral training aimed to reproduce the current state of things in this same society. However, it is worth noting that this process occurs in a contradictory manner. For it is intended that the appropriation of scientific knowledge within the capitalist mode of production enables revolutionary intervention in reality.
\end{abstract}

Keywords: Integral Education; Omniterality; Individuality for itself. 


\section{Introdução}

No Brasil, sobretudo na segunda metade do Século XX, ampliou-se a discussão sobre educação integral. $\mathrm{O}$ educador Anísio Teixeira desempenhou importante papel nesse processo com as experiências que desenvolveu a partir da década de 1930. Posteriormente, Darcy Ribeiro, que se considerava continuador do legado de Anísio Teixeira, implantou no Rio de Janeiro os Centros Integrados de Educação Pública (CIEPs) durante os governos de Leonel Brizola. Na primeira década do Século XXI retomou-se a discussão acerca das políticas de educação integral e tempo integral partindo novamente do pressuposto de que ela possui importante papel no combate às desigualdades sociais. Ou seja, manteve-se o ideal redentor da educação como forma de escamotear as profundas desigualdades sociais e econômicas que, essencialmente, estão na origem das desigualdades educacionais. A ampliação do debate está ocorrendo tendo em vista a implantação, por parte do governo federal, de programas que ampliam a jornada escolar e concebem a proposta de educação integral em uma determinada perspectiva.

Objetivando explicitar as concepções de educação integral debatidas historicamente no Brasil, inicialmente abordam-se as concepções e práticas de educação integral no Brasil ao longo do Século XX. Em seguida, aborda-se a concepção de educação integral na perspectiva marxista em contraponto às concepções burguesas que tem orientado as experiências históricas no Brasil. Por fim, discute-se acerca da impossibilidade de uma educação integral na perspectiva da omnilateralidade no interior das relações capitalistas de produção, destacando, no entanto, a forma contraditória como o capitalismo se desenvolve impedindo a formação humana omnilateral ao negar o acesso de forma universal aos conhecimentos produzidos historicamente pela humanidade, ao mesmo tempo em que cria as condições concretas para a formação da individualidade livre e universal.

\section{Concepções e práticas de educação integral no Brasil}

O educador Anísio Teixeira está entre os protagonistas no campo da educação pública no Brasil, cujas experiências institucionalizadas traziam em suas propostas a ideia de educação integral. Em 1934 Anísio Teixeira cria, no Rio de Janeiro, cinco escolas de educação de tempo integral. Em 1950 propôs e organizou sob sua direção, na Bahia, a criação do Centro Educacional Carneiro Ribeiro que teve suas instalações físicas concluídas apenas em 1964.

Outra proposta foi conduzida por Darcy Ribeiro durante dois mandatos de Leonel Brizola como governador do Estado do Rio de Janeiro. O primeiro entre 1983 e 1986 e o segundo entre 1991 e 1994. Essa iniciativa foi denominada de CIEPs. Em São Paulo, no período de 1986 a 1993, buscou-se implantar o Programa de Formação Integral da Criança (PROFIC). EM 1991 foram criados os Centros Integrados de Atendimento à Criança e ao Adolescente (CIACS). Nos últimos anos, outras experiências no Brasil estão sendo realizadas ampliando a jornada escolar e utilizando o conceito de educação integral (SILVA; SILVA, 2012, p. 51).

Bomeny (2009), referindo-se aos CIEPs, afirma que esta proposta trazia em sua concepção uma perspectiva redentora para a sociedade brasileira por meio da educação. Darcy Ribeiro defendeu publicamente a educação "[...] como chave para o desenvolvimento do País. De seu ponto de vista, seria a estratégia de médio prazo mais 
eficaz para a redenção brasileira, o que, segundo ele, se traduzia na incorporação do povo aos benefícios restritos à elite" (BOMENY, 2009, p. 114).

No que diz respeito às concepções de educação integral e como estas tem influenciado as experiências postas em prática no Brasil, Silva e Silva (2012) assinalam aquelas com incidência maior no país: concepção conservadora-integralista, liberalpragmatista, socialista anarquista e a socialista marxista.

Ao discorrer acerca da concepção de educação do movimento integralista, Coelho (2004, p. 6), afirma que este falava de educação integral nos escritos de Plínio Salgado, em textos de militantes representativos do movimento, assim como em documentos que compõem a Enciclopédia do integralismo. Nesta Enciclopédia afirma-se que "[...] em todos esses escritos, um único pensamento: o da educação integral para o homem integral" (ENCICLOPÉDIA DO INTEGRALISMO, Apud COELHO, 2004, p. 6). No integralismo a ênfase da formação humana "recai na espiritualidade, no nacionalismo cívico, na disciplina, ou seja, em fundamentos político-conservadores" (COELHO, 2004, p. 7).

O ideal educativo apontado pelo movimento integralista, segundo Cavaliere (2002, p. 46) se propõe a educar o homem todo. Na perspectiva integralista o homem todo significa "[...] o conjunto do homem físico, do homem intelectual, do homem cívico e do homem espiritual [...]. Ao homem espiritual ensinava os deveres para com Deus, para consigo e para o próximo". No tocante ao homem físico, a educação integral deveria oferecer "os meios adequados aos cuidados da saúde, à conservação da robustez, à higienização, à valorização nacional da força muscular [...]” (CAVALIERE, 2002, p. 46).

Em síntese, ao destacar conceitos como nacionalismo, disciplina, espiritualidade, o movimento integralista propunha uma educação com pressupostos políticos e ideológicos fortemente marcados por um ideal conservador e funcionalista, portanto, interessado em reproduzir o status quo vigente.

A concepção liberal-pragmatista vincula-se ao movimento escolanovista que adentrou no Brasil já na década de 1920 e ganhou força nas décadas seguintes. O principal representante dessa corrente é Anísio Teixeira. Ao discorrer sobre a defesa de uma educação integral por Anísio Teixeira, Tenório e Schelbauer (2014), afirmam que a perspectiva de educação integral desse autor perpassou o Manifesto dos Pioneiros da Educação Nova lançado em 1932, a criação do Centro Educacional Carneiro Ribeiro na Bahia e a Lei de Diretrizes e Bases da Educação Nacional (LDB) aprovada em 1961.

O pensamento de Anísio Teixeira foi fortemente influenciado pelo pragmatismo de John Dewey, autor estadunidense. Com base nas ideias de Dewey, concebeu a educação integral a partir da compreensão de que o desenvolvimento e a formação do homem se dão na ação, no ato de fazer e não através da transmissão formal de conteúdos (CAVALIERE, 2010, p. 258). Esta autora destaca ainda o viés funcionalista da proposta de educação integral de Anísio Teixeira. Nesse sentido, a educação é compreendida como um processo que e distribui os homens pelas ocupações oferecidas pela sociedade:

Só posso compreender a educação como o processo de preparação e distribuição de homens pelas diversas ocupações que caracterizam a vida humana, na atualidade. Três anos de escola elementar (...) não bastam para habilitá-los às ocupações corriqueiras, nem ao menos os preparam para fazer um pouco melhor o que terão que fazer de qualquer modo, mesmo levando a mais rudimentar das existências (Teixeira, 1997, p. 81). 
Evidencia-se, desse modo, o caráter limitado das propostas de Anísio Teixeira, não obstante a luta desse educador pela democratização da escola pública no Brasil.

\section{Concepção de educação integral na perspectiva marxista}

As diversas correntes do ideário pós-moderno têm atacado e acusado o marxismo de realizar uma análise economicista e objetivista das sociedades. As categorias centrais do marxismo como luta de classes, totalidade e contradição são consideradas obsoletas. $\mathrm{O}$ marxismo também é acusado de negar a individualidade diluindo-a na totalidade histórica e econômica. A universalidade dos conhecimentos objetivos é considerada pelos pósmodernos como uma ilusão a ser combatida e em seu lugar enfatizam-se as múltiplas culturas e os conhecimentos do senso comum presentes nas especificidades locais.

Duarte e Saviani (2010, p. 425), explicitam a contradição presente nas ideias atualmente dominantes. O marxismo é situado pelos pós-modernos como um pensamento cuja origem está na modernidade, portanto, marcado pela metafísica do sujeito e, simultaneamente, é criticado por supostamente limitar-se a análises totalizantes, objetivantes e sociologizantes excluindo, dessa maneira, os sujeitos e os aspectos psicológicos. Os autores citados afirmam que é necessário “[...] restabelecer o entendimento de que o pensamento de Marx é caracteristicamente antimetafísico, manifestando-se provavelmente como a forma mais acabada de um modo de filosofar que unifica, na história, o conteúdo e a forma da filosofia" (DUARTE; SAVIANI, 2010, p. 425). Nesse sentido, o marxismo constitui-se como "[...] uma filosofia ao mesmo tempo histórica e historicizadora em que estão em causa não os indivíduos ou sujeitos abstratos, mas os indivíduos reais, sujeitos históricos que se constituem como síntese de relações sociais" (DUARTE; SAVIANI, 2010, p. 425).

Nessa direção, de acordo com Saviani (2013, p. 26), não é possível falar em neutralidade da educação escolar tendo em vista os interesses antagônicos das classes que compõem a sociedade capitalista. Nesse sentido, se a educação escolar for posta a serviço do desenvolvimento do capital, e consequentemente da classe dominante, terá um papel distinto caso se posicione favorável aos interesses da classe trabalhadora. No caso da sociedade brasileira, segundo Saviani (2013, p. 27) "[...] a educação escolar move-se inevitavelmente no âmbito da luta de classes quer se tenha ou não consciência disso, quer se queira ou não assumir essa condição". O autor destaca ainda, que "[...] ignorar essa situação ou pretender manter-se neutro é uma forma objetivamente eficiente de agir em consonância com os interesses dominantes" (SAVIANI, 2013, p. 27).

Desta forma, para Duarte e Saviani (2010, p. 428), enquanto vigorarem relações de produção que impossibilitem aos sujeitos relacionarem-se com o produto do trabalho humano de forma não alienada, estranhada, não será igualmente possível a apropriação da atividade histórica humana por parte de todos os indivíduos, ou seja, "a relação dos indivíduos com os produtos da atividade humana não pode transformar-se radicalmente se não ocorrer a mesma transformação da relação entre o sujeito e sua própria atividade". A mudança radical da relação do ser humano com seu trabalho numa sociedade comunista irá ocorrer na medida em "[...] que a atividade deixe de ser um meio para a satisfação de necessidades externas a ela e passe a ser ela mesma um processo no qual o sujeito se desenvolve e se realiza como um ser humano" (DUARTE; SAVIANI, 2010, p. 428).

No entanto, Duarte (1999, p. 175), ao tratar da individualidade para-si, destaca que a individualidade livre e universal desenvolve-se ainda durante o processo de superação da sociedade capitalista. Nesse sentido, não é possível ver a formação da individualidade 
para-si “[...] apenas como conseqüência da instauração de novas estruturas políticas e econômicas, mas sim uma condição fundamental para o próprio processo de transformação das estruturas atuais e das relações sociais alienadas que as mantêm". A categoria individualidade para-si, expressa, portanto, no que diz respeito à formação do indivíduo:

[...] a busca de superação do caráter espontâneo e natural com que sua individualidade resulta da 'síntese das inúmeras relações sociais', rumo a uma individualidade que seja a síntese da relação consciente do indivíduo para com as condições particulares de sua existência, mediada pela relação consciente com as objetivações do gênero humano (DUARTE, 1999, p. 15).

O autor assinala, ainda, que o capitalismo não desenvolve apenas a individualidade universal, de forma abstrata, por meio da inserção dos homens no mercado mundial através da troca de mercadorias. Nesse processo produz, contraditoriamente, "um certo grau de realização da individualidade livre e universal" (DUARTE, 1999, p. 175). Nessa perspectiva, cabe fazer avançar, ainda no âmbito da sociedade capitalista, essa individualidade.

Duarte $(2008$, p. 48) argumenta que a dialética entre objetivação e apropriação é a "dinâmica essencial da produção e reprodução da realidade humana". De acordo com esse autor, a relação entre objetivação e apropriação se realiza invariavelmente com outros indivíduos no interior de relações concretas. Esses indivíduos "[...] atuam como mediadores entre ele e o mundo humano, o mundo da atividade humana objetivada" (DUARTE, 1999, p. 48). A formação humana difere essencialmente dos animais precisamente porque estes não produzem história. Nesse sentido, os resultados da história social devem ser apropriados pelos indivíduos para que estes se objetivem no interior do processo histórico.

No processo de apropriação dos resultados históricos com características universais produzidos pelo gênero humano, denominados por Duarte (1999) de generecidade para-si, por parte dos indivíduos, a educação escolar pública deveria desempenhar papel central. No entanto, dada a divisão da sociedade entre classes antagônicas no Brasil, esse processo de transmissão/apropriação está sendo obstaculizado pelos interesses dominantes.

A escola sempre foi utilizada pelas classes dirigentes como uma arma em suas mãos. No entanto, apesar do claro direcionamento da escola dado pela burguesia, esta não possui interesse algum em caracterizar a escola como uma instituição comprometida com a classe dominante. Esse mascaramento da natureza da escola na sociedade capitalista se dá em função de a que minoria burguesa tem clareza de que uma escola não subordinada aos seus interesses colabora com a destruição de sua dominação (PISTRAK, 2003, p. 30).

Diversamente da ocultação do caráter da escola produzida pela burguesia, a escola da classe trabalhadora, durante a ditadura do proletariado, não tem nenhum interesse em mascarar seus objetivos e interesses de classe. Busca, ao contrário, explicitá-los evidenciando o seu compromisso com a superação do modo de produção capitalista e a construção de uma nova sociedade onde as classes sociais estariam suprimidas. Entre os objetivos da nova escola, Pistrak (2003, p. 31) destaca "a formação de um homem que se considere como membro da coletividade internacional constituída pela classe operária em luta contra o regime agonizante e por uma vida nova, por um novo regime social em que as classes sociais não existam mais". Concretamente, o autor (PISTRAK, 2003, p. 31), argumenta que é necessária a compreensão pela nova geração da "natureza da luta travada 
atualmente pela humanidade, [...] qual o espaço ocupado pela classe explorada nessa luta; [...] qual o espaço que deve ser ocupado por cada adolescente; e [...] que cada um saiba [...] travar a luta pela destruição das formas inúteis" com a consequente substituição por um edifício novo. Nessa direção, o autor (PISTRAK, 2003, p. 37, grifos do autor) assinala que a escola:

[...] deve explicar a cada um os objetivos da luta, contra o que lutar e por que meios, o que cada aluno deve criar e construir, e como. Se resumíssemos agora as deduções que formulamos a respeito do ensino, diremos que o conteúdo do ensino deve servir para armar a criança para a luta e para a criação da nova ordem, que os métodos de trabalho devem permitir a utilização prática destas armas e que os objetivos do ensino e da educação consistem numa transformação dos conhecimentos em concepções ativas.

Pistrak (2009, p. 122), argumenta que a escola deve formar os alunos no marxismo. Isso é possível tendo em vista que o marxismo não fornece apenas um método de análise das relações sociais vigentes esclarecendo sua essência, mas também oferece um método de transformação da realidade atual a partir de sua análise. O autor alerta, no entanto, que não é possível à escola "dar a fundamentação filosófica e científica completa e segura do marxismo, que ela poderá sintetizar e generalizar num sistema lógico de visão de mundo materialista" (PISTRAK, 2009, 122). Apesar dessa limitação, dado o nível dos estudantes, o autor afirma que a visão de mundo marxista e [...] "o acesso correto aos fenômenos sociais, por assim dizer, a escola pode e deve desenvolver e formar no estudante, pela intuição marxista (PISTRAK, 2009, 122). Desse modo, é possível tornar acessível ao estudante uma concepção materialista na perspectiva dialética considerando, entretanto, os limites impostos pelo processo de desenvolvimento da coletividade e de cada indivíduo em particular.

\section{A impossibilidade da educação integral na perspectiva da omnilateralidade no modo de produção capitalista}

Não obstante o fato de que a educação propriamente dita não tenha sido objeto específico de estudo de Marx e Engels, é com a obra destes autores que se torna possível estabelecer uma clara relação entre as condições materiais de uma dada sociedade, e suas principais classes, com a educação oferecida a estas mesmas classes.

Ao tratar da perspectiva pedagógica de Karl Marx e especificamente do conceito de omnilateralidade, Manacorda (1991, p. 81), afirma que este conceito diz respeito ao momento histórico em que o homem chega:

[...] a uma totalidade de capacidades produtivas e, ao mesmo tempo, a uma totalidade de capacidades de consumo e prazeres, em que se deve considerar sobretudo o gozo daqueles bens espirituais, além dos materiais, e dos quais o trabalhador tem estado excluído em consequência da divisão do trabalho.

Nesse sentido, em Marx, a formação integral do ser humano, ou seja, omnilateral, está alicerçada nas condições materiais em um dado desenvolvimento da história em que a divisão do trabalho presente na sociedade capitalista seja superada por meio de uma revolução dirigida pelo proletariado. 
Lombardi (2010, p. 332), ao apresentar seu entendimento acerca dos escritos de Suchodolski, Manacorda, Dangeville e Nogueira, afirma que, em linhas gerais, os trabalhos que estes autores publicaram possibilitam "organizar a contribuição marxiana à educação" em três grandes aspectos: crítica à educação, ao ensino e à qualificação profissional burguesa, relação do proletariado com a ciência, a cultura e a educação e educação comunista e formação integral do homem.

No que diz respeito ao primeiro aspecto, Lombardi (2010, p. 332), argumenta que da mesma forma que Marx e Engels apresentaram uma profunda crítica à economia política burguesa, "também dirigiram ao ensino burguês uma aguda e profunda crítica, desnudando a relação entre a educação e as condições de vida das classes fundamentais da sociedade burguesa". Já no que diz respeito ao tratamento dado por Marx e Engels ao tema da relação do proletariado com a cultura e a ciência, deixava claro como estes "entendiam a ciência a serviço do capital, o processo de alienação resultante do processo de trabalho industrial e o aparelhamento burguês da escola, bem como a importância da educação para a formação da consciência". Quanto ao terceiro aspecto, educação comunista e formação integral do homem, a educação é apresentada como "articuladora do fazer e do pensar - a superação da monotecnia pela politecnia” (LOMBARDI, 2010, p. 332).

A concepção educacional de Marx e Engels partia da crítica à sociedade burguesa tendo como horizonte a superação revolucionária desta e instauração da sociedade comunista constituindo-se o reino da liberdade. Somente com a "instauração do comunismo a educação estará a serviço do homem e, rearticulando o trabalho manual e a atividade intelectual, deverá voltar-se plenamente à formação integral do homem" (LOMBARDI, 2010, p. 332).

Marx e Engels (1987, p. 126), no Manifesto comunista de 1848, ao apresentarem as medidas que o proletariado deverá adotar na primeira etapa da revolução proletária, ou seja, no momento em que estiver exercendo a ditadura do proletariado em substituição a ditadura da burguesia, defendem, na última medida proposta, "educação pública gratuita para todas as crianças; abolição do trabalho infantil nas fábricas, tal como é feito atualmente; combinação da educação com a produção material, etc". Na sequência, discutem o processo de transição de uma sociedade fundada em antagonismos de classe para outra onde a dominação é extinta e com ela as classes em geral:

Quando, no curso do desenvolvimento, desaparecerem as distinções de classe e toda a produção concentrar-se nas mãos dos indivíduos associados, o poder público perderá seu caráter político. O poder político propriamente dito é o poder organizado de uma classe para opressão de outra. Se o proletariado, em sua luta contra a burguesia, é forçado pelas circunstâncias a organizar-se como dominante, se se torna, mediante uma revolução, a classe dominante e, como tal, destrói violentamente as antigas relações de produção, então destrói também, juntamente com estas relações, as condições de existência dos antagonismos de classes, destrói as classes em geral e, com isso, extingue sua própria dominação de classe (MARX; ENGELS, 1987, p. 126).

Somente com o desaparecimento dos antagonismos de classe é possível surgir "uma associação onde o livre desenvolvimento de cada um é a condição do livre 
desenvolvimento de todos" (MARX ; ENGELS, 1987, p. 126). Ainda de acordo com esses autores:

Por instrução nós entendemos três coisas: 1. Educação intelectual. 2. Educação corporal, tal como a que se consegue com os exercícios de ginástica e militares. 3. Educação tecnológica, que recolhe os princípios gerais e de caráter científico de todo o processo de produção e, ao mesmo tempo, inicia as crianças e os adolescentes no manejo de ferramentas elementares dos diversos ramos industriais. A divisão das crianças e adolescentes em três categorias, de nove a dezoito anos, deve corresponder um curso graduado e progressivo para sua educação intelectual, corporal e politécnica. Os gastos com tais escolas politécnicas serão parcialmente cobertos com a venda de seus próprios produtos. Esta combinação de trabalho produtivo pago com a educação intelectual, os exercícios corporais e a formação politécnica elevará a classe operária acima das classes burguesa e aristocrática (MARX; ENGELS, 2004, p. 68-69).

Assim, a sociedade capitalista não oferece as condições concretas para possibilitar educação integral tendo em vista a unilateralidade presente nos processos de formação. No entanto, Marx (Apud DUARTE; SAVIANI, 2010, p. 430), ao destacar o processo contraditório inerente ao capitalismo, assinala que todo o seu desenvolvimento ocorre de modo antagônico produzindo as condições concretas para que seja definitivamente abolido. Isso se dá em função da permanente necessidade de elaborar as forças produtivas, a ciência e a riqueza universal. No interior do capitalismo esse desenvolvimento aliena o trabalhador cuja riqueza por ele produzida não lhe pertence e causa sua pobreza. Nesse processo o capital desenvolve o mercado mundial, universaliza as comunicações criando, portanto, uma base que contem a potencialidade do desenvolvimento universal das forças produtivas e da riqueza. De acordo com Marx (Apud DUARTE; SAVIANI, 2010, p. 430, grifos do autor), sobre esta base estão contidas as condições concretas para o desenvolvimento real dos indivíduos tendo em vista que é a partir dela que "[...] cada barreira é constantemente superada" proporcionando a consciência de que "[...] nenhum limite pode ser considerado como sagrado. A universalidade do indivíduo já não se realiza no pensamento ou na imaginação; está viva em suas relações teóricas e práticas".

Na mesma perspectiva, Manacorda (1991) afirma que, não obstante o fato de Marx constatar a inviabilidade da formação de um homem inteiro na sociedade classista, o operário comunista é exaltado "como homem moral e intelectualmente positivo já na realidade da época” (MANACORDA, 1991, 76).

Estas afirmações estão em consonância com o preconizado por Karl Marx (2007, p. 537), em sua terceira tese sobre Feuerbach, ao se contrapor ao materialismo mecanicista para o qual "[...] os homens são produtos das circunstâncias e da educação, de que homens modificados são, portanto, produto de outras circunstâncias e de uma educação modificada [...]”. Esta concepção, para Marx (2007, p. 537), “[...] esquece que as circunstâncias são modificadas precisamente pelos homens e que o próprio educador tem de ser educado". Para superar o dualismo presente no materialismo mecanicista já que divide a sociedade em duas partes, uma das quais é colocada acima da própria sociedade, Marx (2007, 538, grifos do autor) assinala que "coincidência entre a alteração das circunstâncias e a atividade humana só pode ser apreendida e racionalmente entendida como prática 
revolucionária". Desse modo, a educação como parte da práxis social possui papel relevante no processo revolucionário de superação da sociedade de classes e não pode ser vista como mero reflexo das estruturas econômicas vigentes.

\section{Conclusão}

Neste trabalho discute-se acerca das concepções de educação integral que tem permeado o debate sobre esta temática no Brasil ao longo do Século XX e início do XXI. As experiências implantadas estavam fundamentadas numa perspectiva redentora da educação escolar. Na atualidade o debate ressurgiu e as propostas de educação integral são apresentadas como meio para o desenvolvimento econômico, o alívio à pobreza e redução das desigualdades sociais.

Nesse sentido, conclui-se que nas propostas de educação integral concebidas e implantadas no Brasil até o momento não está presente uma análise no que diz respeito às relações estabelecidas no âmbito da produção social e os processos educativos, especificamente a educação escolar. Desta forma, oculta-se que a sociedade capitalista não oferece as condições concretas para possibilitar educação integral tendo em vista a unilateralidade presente nos processos de formação.

Dada a divisão entre classes sociais antagônicas que compõem a sociedade brasileira, compreende-se a partir das contribuições de Marx e Engels e de autores fundamentados nessa perspectiva, que a educação escolar destinada à classe trabalhadora não terá como objetivo formar os indivíduos desenvolvendo-os integralmente no sentido da superação da unilateralidade da educação burguesa. Cabe destacar, todavia, a contradição inerente ao modo de produção capitalista que desenvolve as condições concretas para a sua própria abolição permitindo, mesmo que limitadamente, a formação da individualidade livre e universal.

\section{Referências}

BOMENY, H. A escola no Brasil de Darcy Ribeiro. MAURÍCIO, L. V. (Org.). Educação integral e tempo integral. Em Aberto. Brasília, v. 22, n. 80, p. 1-165. Abr. 2009.

CAVALIERE. A. Educação Integral: uma nova identidade para a escola brasileira? In: Educ. Soc., Campinas, vol. 23, n. 81, p. 247-270, dez. 2002.

2010.

Anísio Teixeira e a educação integral. Paidéia, v. 20, n. 46, p. 249-259, maio-ago.

COELHO. L. M. C. da C. Educação integral: Concepções e práticas na educação fundamental. In: 27 a Reunião Anual da ANPEd, 2004, Caxambu. Sociedade, democracia e educação: qual universidade? Caxambu: 2004.

DUARTE, N. A individualidade para-si: contribuições a uma teoria histórico-social da formação do indivíduo. 2. ed. Campinas, SP: Autores Associados, 1999.

Relações entre ontologia e epistemologia e a reflexão filosófica sobre o trabalho educativo. In: Sociedade do conhecimento ou sociedade das ilusões?: quatro ensaios 
crítico-dialéticos em filosofia da educação. I reimpressão. Campinas, SP: Autores Associados, 2008.

SAVIANI, D. A formação humana na perspectiva histórico-ontológica. Revista Brasileira de Educação. Set/Dez. 2010 v. 15 n. 45.

LOMBARDI, J. C. Reflexões sobre educação e ensino na obra de Marx e Engels. $377 \mathrm{f}$. Tese (livre docência) - Universidade Estadual de Campinas, Faculdade de Educação. Campinas, SP: [s.n.], 2010.

MANACORDA, M. A. Marx e a pedagogia moderna. Tradução de Newton Ramos de Oliveira; revisão técnica de Paolo Nosella; prefácio de Dermeval Saviani. São Paulo: Cortez \& Autores Associados, 1991.

MARX, K.; ENGELS, F. Cartas filosóficas e o manifesto comunista de 1848. São Paulo: Moraes, 1987.

Textos sobre educação e ensino. Tradução de Rubens Eduardo Frias. São Paulo: Centauro, 2004.

A ideologia alemã: crítica da mais recente filosofia alemã em seus representantes Feuerbach, B. Bauer e Stirner, e do socialismo alemão em seus diferentes profetas (18451846). Supervisão editorial, Leandro Konder; tradução, Rubens Enderle, Nélio Schneider, Luciano Cavini Martorano. São Paulo: Boitempo, 2007.

PISTRAK, M. M. Fundamentos da escola do trabalho. São Paulo: Expressão popular, 2003.

A escola-comuna. São Paulo: Expressão popular, 2009.

SAVIANI, D. A pedagogia histórico-crítica, as lutas de classe e a educação escolar.

Germinal: Marxismo e Educação em Debate, Salvador, v. 5, n. 2, p. 25-46, dez. 2013.

SILVA, J. A. de A. da; SILVA, K. N. P. da. Educação integral no Brasil de hoje. Recife: CRV, 2012.

TEIXEIRA, A. Educação para a democracia. Rio de Janeiro: UFRJ, 1997.

TENÓRIO, A. F.; SCHELBAUER, A. R. A defesa pela educação integral na obra de Anísio Teixeira. Disponível em:

http://www.histedbr.fe.unicamp.br/acer_histedbr/jornada/jornada7/_GT1\%20PDF/A\%20D EFESA\%20PELA\%20EDUCA\%C7\%C3O\%20INTEGRAL\%20NA\%20OBRA\%20DE\%2 0AN\%CDSIO.pdf. Acesso em: 10 set. 2014.

Recebido: jun/2015 Aprovado: jul/2015 